PAPER

\title{
Experienced fatigue in facioscapulohumeral dystrophy, myotonic dystrophy, and HMSN-I
}

\author{
J S Kalkman, M L Schillings, S P van der Werf, G W Padberg, M J Zwarts, B G M van Engelen, \\ G Bleijenberg
}

J Neurol Neurosurg Psychiatry 2005;76:1406-1409. doi: 10.1136/jnnp.2004.050005

See end of article for authors' affiliations

.....................

Correspondence to: J S Kalkman, Expert Centre Chronic Fatigue (627), Radboud University Nijmegen Medical Centre, PO Box 9101, $6500 \mathrm{HB}$

Nijmegen, Netherlands; $;$. kalkman@nkcv.umcn.nl

Received 16 July 2004 In revised form

13 January 2005

Accepted 13 January 2005

\begin{abstract}
Objective: To assess the prevalence of severe fatigue and its relation to functional impairment in daily life in patients with relatively common types of neuromuscular disorders.

Methods: 598 patients with a neuromuscular disease were studied (139 with facioscapulohumeral dystrophy, 322 with adult onset myotonic dystrophy, and 137 with hereditary motor and sensory neuropathy type I). Fatigue severity was assessed with Checklist Individual Strength (CIS-fatigue). Functional impairments in daily life were measured with the short form 36 item health questionnaire (SF36).

Results: The three different neuromuscular patient groups were of similar age and sex. Severe experienced fatigue was reported by $61-74 \%$ of the patients. Severely fatigued patients had more problems with physical functioning, social functioning, mental health, bodily pain, and general health perception. There were some differences between the three disorders in the effects of fatigue.

Conclusions: Severe fatigue is reported by the majority of patients with relatively common types of neuromuscular disorders. Because experienced fatigue severity is associated with the severity of various functional impairments in daily life, it is a clinically and socially relevant problem in this group of patients.
\end{abstract}

F atigue has been defined as an overwhelming sense of tiredness, lack of energy, and feeling of exhaustion and is not the same as weakness. ${ }^{1}$ Fatigue is a common symptom in different neurological disorders such as multiple sclerosis, Parkinson's disease, and stroke..$^{1-7}$ In these patient populations it was found that the experience of severe fatigue can be a major determinant of disability and influences the quality of life. Surprisingly, fatigue in neuromuscular disorders has received little attention, though there have been studies in patients with particular neuromuscular disorders. Paul et al showed that $82 \%$ of a group of patients with myasthenia gravis reported fatigue as a regular symptom of their disease. ${ }^{8}$ A study by Berlly et al showed that $68 \%$ of a group of post-poliomyelitis patients reported daily fatigue. Half these fatigued patients noted that their fatigue had led to the need for assistance in daily life. ${ }^{9}$ In a group of patients with immune mediated polyneuropathies it was found that fatigue was a prominent and highly disabling symptom. ${ }^{10}$ Herlofson and Larsen showed that fatigued patients with Parkinson's disease reported more problems in areas of functional limitation. ${ }^{11}$ Fisk et al found that fatigue had a significant effect on the general health status in patients with multiple sclerosis. ${ }^{12}$ The impact of fatigue in health related quality of life in patients with neuromuscular disorders has not been studied so far.

Clinical experience and preliminary findings of our research group indicated that many patients with a neuromuscular disorder also experience severe fatigue and consider it an important problem. ${ }^{13}$ Most psychological studies in neuromuscular disorders, however, have focused mainly on disability or loss of quality of life, and did not address the problem of experienced fatigue among different neuromuscular disorders. ${ }^{14-16}$ Currently, no cross sectional study has compared the presence and severity of fatigue in various neuromuscular diseases using validated instruments.

This study concerned three genetically well defined, homogeneous, and large populations of patients with relatively common neuromuscular disorders, namely facioscapulohumeral muscular dystrophy (FSHD), adult onset myotonic dystrophy (MD), and hereditary motor and sensory neuropathy type I (HMSN-I). FSHD is an autosomal dominantly inherited myopathy. ${ }^{17} \mathrm{MD}$ is the most common form of muscular dystrophy and is an autosomal dominant hereditary multisystem disease involving skeletal muscles, eye, heart, lungs, gastrointestinal tract, bone, skin, and central and peripheral nervous systems. ${ }^{18} \mathrm{HMSN}-\mathrm{I}$ is the most common genetic disorder affecting the peripheral nervous system. ${ }^{19-21}$ Thus, this study compared fatigue experienced in three different patient populations with neuromuscular disease, including a myopathy, a multisystem disorder, and a neuropathy.

Our research group has developed a multidimensional assessment method to measure fatigue in several chronic disorders. ${ }^{22-26}$ In this study, besides fatigue severity we also investigated the relation between fatigue and functional impairment in daily life.

Health related quality of life scales, such as the short form 36 item health survey questionnaire (SF-36), might be useful to assess important domains of health and various aspects of impairment from the patient's perspective. ${ }^{27}$ We chose the SF-36 as the most widely used generic health related scale to evaluate the potential impact of fatigue on different components of functional impairment in daily life in patients with a neuromuscular disorder.

In this study we addressed the following questions. How many patients with these neuromuscular disorders experience severe fatigue? Are there differences in fatigue severity, demographic variables, and various functional impairments between the different neuromuscular disorders? And what is the contribution of physical functioning, social functioning,

Abbreviations: CIS, Checklist Individual Strength; FSHD, facioscapulohumeral muscular dystrophy; HMSN-I, hereditary motor and sensory neuropathy type I; MD, adult onset myotonic dystrophy; SF36,36 item short form general health questionnaire 


\begin{tabular}{|c|c|c|c|}
\hline & $\begin{array}{l}\text { FSHD } \\
(n=139)\end{array}$ & $\begin{array}{l}\text { MD } \\
(n=322)\end{array}$ & $\begin{array}{l}\text { HMSN-I } \\
(n=137)\end{array}$ \\
\hline Age (years) (mean (SD)) & $43.7(10.1)$ & $43(10)$ & $42.5(10.7)$ \\
\hline Age range (years) & 22 to 61 & 18 to 63 & 19 to 63 \\
\hline $\operatorname{Sex}(M / F)(\%)$ & $49 / 51$ & $47 / 53$ & $41 / 59$ \\
\hline \multicolumn{4}{|l|}{ Marital status } \\
\hline Married/living together & $74 \%$ & $70 \%$ & $69 \%$ \\
\hline Single & $25 \%$ & $30 \%$ & $31 \%$ \\
\hline Missing information & $1 \%$ & - & - \\
\hline \multicolumn{4}{|l|}{ Education level ${ }^{*}$} \\
\hline Lower & $32 \%$ & $53 \%$ & $28 \%$ \\
\hline Intermediate & $34 \%$ & $28 \%$ & $27 \%$ \\
\hline Upper & $34 \%$ & $19 \%$ & $29 \%$ \\
\hline Missing information & $1 \%$ & - & - \\
\hline \multicolumn{4}{|c|}{$\begin{array}{l}\text { *Significant difference between MD and FSHD and between MD and } \\
\text { HMSN-I ( }<<0.05) \text {. } \\
\text { FSHD, facioscapulohumeral muscular dystrophy; HMSN-I, hereditary } \\
\text { motor and sensory neuropathy type I; MD, adult onset myotonic } \\
\text { dystrophy. }\end{array}$} \\
\hline
\end{tabular}

mental health, and bodily pain to fatigue severity in three different relatively common neuromuscular disorders?

\section{METHODS}

\section{Patients}

Adult patients aged 18 to 65 years with a definite diagnosis who could be classified into one of the three neuromuscular disease categories (FSHD, MD, HMSN-I) were asked to participate. Some of the patients were recruited from the Neuromuscular Centre, Radboud University Nijmegen Medical Centre in the Netherlands. The remainder were recruited from the Dutch Neuromuscular Diseases Association (Vereniging Spierziekten Nederland, VSN).

In all, 900 patients were informed by a letter and received a booklet with questionnaires (described below) at home. Subjects were asked what diagnosis had been made and if this was done by a neurologist or a clinical geneticist.

We used a cross sectional design to assess fatigue in patients with a neuromuscular disorder. Written information about the purpose of the study was provided to all the patients. The study was approved by the local ethics committee.

\section{Fatigue severity}

The Checklist Individual Strength (CIS) is a 20 item questionnaire and measures the following four separate aspects of fatigue during the previous two weeks: fatigue severity (eight items, score range 8 to 56), concentration problems (five items, score range 5 to 35 ), reduced motivation (four items, score range 4 to 28 ), and reduced activity (three items, score range 3 to 21). Each item was scored on a seven point Likert scale. High scores indicated high levels of fatigue, high levels of concentration problems, low motivation, and low levels of activity. ${ }^{22}$ The CIS had good internal consistency and split-half reliability. ${ }^{28}$ A CISfatigue score of 35 or more was used to identify severe fatigue. ${ }^{29}$

\section{Functional impairment in daily life}

The following subscales of the SF-36 were used to assess different areas of functional impairment in daily life: physical functioning, social functioning, role limitations caused by physical health problems, role limitations caused by emotional problems, mental health, bodily pain, and general health perception. ${ }^{30}$ The transformed scores for all SF-36 scales ranged from 0 to 100. For each subscale a higher score indicated better functioning or less pain.

\section{Statistics}

Data analysis was carried out using SPSS for Windows (version 11.0). Descriptive statistics were used to describe the sample. Normality was tested according to the KolmogorovSmirnov test. We used $t$ tests, $\chi^{2}$ tests, and one way analysis of variance (ANOVA) to test for differences between groups. Where overall significance was shown, the Bonferroni correction was applied to compare the three patient groups. Probability $(p)$ values of $\leqslant 0.05$ were regarded as statistically significant. Correlations were calculated with the Pearson coefficient $(r)$. In order to examine the contribution of physical functioning, social functioning, mental health, and bodily pain in relation to fatigue severity, linear regression analyses (enter method) were performed.

\section{RESULTS}

From the 647 adult patients (72\%) who returned the questionnaires, 49 were excluded for the following reasons: no diagnosis of FSHD, MD, or HMSN-I $(\mathrm{n}=30)$; incomplete booklets $(n=19)$. In all, 598 patients fitted the inclusion criteria and completed the questionnaires (66\%). This group consisted of 139 patients with FSHD, 322 with MD, and 137 with HMSN-I. Diagnoses in a quarter of these patients were made at our hospital according to established criteria. ${ }^{31}$ Results from this subgroup did not differ from the results of the group as a whole. Demographic characteristics of the three groups are listed in table 1 . No significant differences were found in age, sex, or marital status between the three groups. The MD group had a significantly lower level of education than the two other groups.

\section{Fatigue and functional impairment in FSHD, MD, and HMSN}

All patient groups experienced high levels of fatigue. The mean (SD) CIS-fatigue score in the FSHD group was 36.5 (12.5), in the MD group 40.4 (11.8), and in the HMSN group 37.4 (12.2). In the FSHD group 61\% were severely fatigued, in the MD group $74 \%$, and in the HMSN group $64 \%$.

Table 2 shows a comparison of functional impairments in daily life between the three patient groups. The MD group reported having significantly more concentration problems, higher levels of reduced motivation, and reduced levels of activity. The MD group perceived lower general health but experienced less bodily pain than the FSHD and HMSN patients.

\section{Age related problems}

In the FSHD and MD groups, age correlated significantly with fatigue severity (FSHD: $r=0.19, \mathrm{p}=0.002 ; \mathrm{MD}$ : $r=0.17, \mathrm{p}=0.002)$. In all three patient groups, higher age was associated with more impairment in physical functioning and more bodily pain. Among the MD patients, age correlated significantly with all subscales of the SF-36 and with reduced motivation and reduced activity on the CIS.

\section{Severely fatigued patients}

Severely fatigued patients (CIS-fatigue $\geqslant 35$ ) were compared with less fatigued patients (CIS-fatigue $<35$ ) within the three neuromuscular disorders. Severely fatigued FSHD patients, MD patients, and HMSN patients had more concentration problems, higher scores on reduced motivation, and reduced levels of physical activity. Severely fatigued patients also had significantly lower scores at all subscales of the SF-36.

\section{Contribution of different dimensions to fatigue severity}

Regression analyses were carried out to examine the contribution of different dimensions in relation to fatigue severity (table 3). Separate analyses were done for each 
Table 2 The main outcome measures in the three patient groups

\begin{tabular}{|c|c|c|c|c|}
\hline & FSHD $(n=139)$ & $M D(n=322)$ & HMSN-I $(n=137)$ & p Value \\
\hline \multicolumn{5}{|l|}{ CIS } \\
\hline CIS-fatigue & $36.5(12.5) \dagger$ & $40.4(11.8)^{*} \ddagger$ & $37.4(12.2) \dagger$ & 0.002 \\
\hline CIS-concentration & $12.3(8.2) \dagger$ & $16.8(8.3)^{*} \ddagger$ & $13.8(8.7) \dagger$ & 0.000 \\
\hline CIS-motivation & $12(5.9) t$ & $16.8(6.6)^{*} \ddagger$ & $12.2(6.1) \dagger$ & 0.000 \\
\hline CIS-activity & $10.1(5.5) \dagger$ & $13.2(5.6)^{*} \ddagger$ & $9.4(5.5) \dagger$ & 0.000 \\
\hline \multicolumn{5}{|l|}{ SF-36 } \\
\hline physical functioning & $45.2(31.4)$ & $48.4(28.2)$ & $53.1(26.4)$ & NS \\
\hline social functioning & $71.6(24.2)$ & $69.9(24.3)$ & $67.5(24.3)$ & NS \\
\hline role limitations physical & $47.9(42)$ & $48.2(39.7)$ & $48.9(39)$ & NS \\
\hline role limitations emotional & $69.5(41.6)$ & $73.9(37.6)$ & $67.4(41.6)$ & NS \\
\hline mental health & 72.6 (17) & 72.7 (18) & $68.9(19.2)$ & NS \\
\hline bodily pain & $66.6(23.8) \dagger$ & $75.4(25.3)^{*} \ddagger$ & $68.5(25.5) \dagger$ & 0.001 \\
\hline general health perception & $51.7(21.6) \dagger$ & $40.5(22.3)^{*} \ddagger$ & $52.5(20.7) \dagger$ & 0.000 \\
\hline
\end{tabular}

Values are mean (SD). A higher value indicates more complaints or impairments. *Significantly different from FSHD, Bonferroni $\mathrm{p}<0.05$. †Significantly different from MD, Bonferroni $p<0.05$. $\ddagger$ Significantly different from HMSN-I, Bonferroni $\mathrm{p}<0.05$.

FSHD, facioscapulohumeral muscular dystrophy; HMSN-I, hereditary motor and sensory neuropathy type I; MD adult onset myotonic dystrophy; SF-36, 36 item short form general health questionnaire.

group, with CIS-fatigue as the dependent variable. In none of the groups did age contribute to fatigue severity. In the FSHD group, physical functioning, social functioning, and bodily pain contributed significantly to fatigue severity; in the MD group, physical functioning and social functioning contributed significantly; in the HMSN group, none of the independent variables contributed significantly. The correlations between CIS-fatigue and the SF-36 subscales were weaker in the HMSN group than in the FSHD or MD group.

\section{DISCUSSION}

As far as we know this is the first cross sectional study in which fatigue has been investigated in three large homogeneous groups of neuromuscular disorders with validated measurements. Our study shows that $61-74 \%$ of the subjects in the investigated groups were severely fatigued. This means that the experience of severe fatigue is a major complaint in most patients with these neuromuscular diseases. In all three groups, being severely fatigued was associated with greater levels of functional impairment in daily life.

The results also showed that patients with myotonic dystrophy had significantly higher scores of severe fatigue, reported more problems with concentration (CIS-concentration), and had more difficulty in initiating and planning (CIS-reduced motivation) than the other two groups. Daytime sleepiness is an established clinical manifestation of myotonic dystrophy. ${ }^{18} 3233$ It is possible that patients with this disease confuse the experience of fatigue with daytime sleepiness, which may have affected the CIS-fatigue scores of the MD group. However, van der Werf et al showed that experienced fatigue, measured with the CIS-fatigue, and daytime sleepiness are different clinical manifestations in myotonic dystrophy. ${ }^{34}$

In addition, we found that MD patients had a lower education level than the FSHD and HMSN patients. These differences may be explained by disease specific problems associated with a multisystem disorder such as myotonic dystrophy. Mental dysfunction-such as reduced intelligence and lower levels of concentration and initiation-has been recognised in myotonic dystrophy, in contrast to the lack of such defects in other disabling neuromuscular disorders. ${ }^{18}{ }^{32}$ Patients with FSHD and HMSN turned out to have higher scores of bodily pain than the MD patients. These results are consistent with reports of presence of pain in other studies in FSHD and HMSN. ${ }^{14-16}$ Pain, particularly back pain, is often cited as a problem but has been poorly studied in MD patients. ${ }^{32}$

Age and fatigue severity did not seem to be related in any of the groups, as no contribution of these variables was found in the regression analyses. Karlsen showed that fatigue severity is not regarded as part of the normal aging process. $^{5}$

The significant correlations between age and functional impairment in daily life suggest that greater age is associated with increasing impairment in physical functioning and bodily pain in all three patient groups. This is in accordance with the progressive nature of these disorders. An increase in physical limitation with age in these conditions is well known. ${ }^{17-19}$ In myotonic dystrophy, age is also correlated with all the other functional impairments. These results are in line with the known differences between these three neuromuscular disorders. ${ }^{18} 32$

Table 3 Linear regression analysis to predict fatigue severity

\begin{tabular}{lcccccc}
\hline \multicolumn{7}{c}{ Dependent variable CIS-fatigue severity } \\
\cline { 2 - 7 } Independent variable & FSHD, $\boldsymbol{\beta}$ & $\begin{array}{l}\text { FSHD, } \\
\mathbf{p} \text { value }\end{array}$ & $\mathbf{M D}, \boldsymbol{\beta}$ & $\begin{array}{l}\text { MD, } \\
\text { p value }\end{array}$ & HSMN-I, $\boldsymbol{\beta}$ & $\begin{array}{l}\text { HMSN-I, } \\
\text { p value }\end{array}$ \\
\hline Physical functioning & -0.228 & 0.010 & -0.398 & 0.000 & -0.188 & 0.056 \\
Social functioning & -0.219 & 0.038 & -0.157 & 0.015 & -0.107 & 0.358 \\
Mental health & -0.031 & 0.725 & -0.112 & 0.048 & -0.166 & 0.121 \\
Bodily pain & -0.195 & 0.042 & -0.062 & 0.284 & -0.146 & 0.121 \\
Age & 0.022 & 0.900 & -0.087 & 0.114 & -0.148 & 0.083 \\
Total $R^{2}$ (adjusted) & 0.238 & & 0.270 & & 0.143 & \\
\hline
\end{tabular}

FSHD, facioscapulohumeral muscular dystrophy; HMSN-I, hereditary motor and sensory neuropathy type I; MD, adult onset myotonic dystrophy. 
Compared with the healthy control data provided in the manual of the Dutch version of the SF-36, the mean scores for our three groups of patients with neuromuscular disease were reduced on all SF-36 subscales. ${ }^{27}$ In addition, the severely fatigued patients in all three groups scored lower than the non-severely fatigued patients, suggesting a relation between fatigue and functional impairment. Herlofson and Larsen showed that fatigued patients with Parkinson's disease reported more problems in areas of functional limitation and that patients with fatigue had more advanced disease than those without fatigue, measured by a disease severity scale for Parkinson's disease. ${ }^{11}$ A study by Fisk et al found that fatigue had a significant effect on general health in patients with multiple sclerosis. ${ }^{12}$ They showed that disease classification and neurological impairment had little bearing on fatigue in patients with multiple sclerosis. In our study we did not use a disease severity scale, so we could not investigate the relation between fatigue severity and disease severity in these disorders.

Regression analyses suggested that physical functioning, bodily pain, and social functioning were related to fatigue severity in FSHD patients. In MD patients only physical functioning and social functioning were related to fatigue severity. In HMSN patients none of the dimensions contributed independently to fatigue severity. Thus in the latter group fatigue is less clearly related to functional impairment. Possibly, factors that we did not measure play a more prominent role in the contribution of fatigue in HMSN.

The impact of fatigue on health related quality of life in patients with neuromuscular disorders has not been studied so far.

There are some methodological limitations to our study. First, its cross sectional design makes it impossible to draw conclusions on the direction of the association. Second, not all the diagnoses were made at our hospital. About a quarter of the patients in the study came from our hospital and the diagnoses of those patients were checked. Nevertheless, this group of patients did not differ in any of the main outcome variables from the remaining patients recruited from the Dutch Neuromuscular Diseases Association.

\section{Conclusions}

Our study shows that the majority of a large sample of patients with relatively common types of neuromuscular disorders experienced severe fatigue. The factors related to fatigue severity appeared to differ in the three types of disorder. Severe fatigue is associated with serious impairment in daily life. Therefore this symptom is a clinically and socially relevant problem in patients with a neuromuscular disorder.

\section{ACKNOWLEDGEMENTS}

The study was funded by the Princess Beatrix Foundation (grant Mar 00-0121) and the Health Research and Developmental Council of the Netherlands (ZON-MW, grant 940-38-024). We thank the Dutch Neuromuscular Diseases Association (Vereniging Spierziekten Nederland, VSN) for the recruitment of participants.

\section{Authors' affiliations}

J S Kalkman, G Bleijenberg, Expert Centre Chronic Fatigue, Radboud University Nijmegen Medical Centre, Nijmegen, Netherlands M L Schillings, M J Zwarts, Department of Clinical Neurophysiology, Institute of Neurology, Radboud University Niimegen Medical Centre S P van der Werf, Department of Medical Psychology, Radboud University Nijmegen Medical Centre
G W Padberg, B G M van Engelen, Neuromuscular Centre Nijmegen, Institute of Neurology, Radboud University Nijmegen Medical Centre

Competing interests: none declared

\section{REFERENCES}

1 Krupp LB, Fatigue. Philadelphia: Butterworth Heinemann 2003.

2 Schwid SR, Covington M, Segal BM, et al. Fatigue in multiple sclerosis: current understanding and future directions. J Rehabil Res Dev 2002;39:211-24.

3 Ford $\mathrm{H}$, Trigwell $\mathrm{P}$, Johnson M. The nature of fatigue in multiple sclerosis. J Psychosom Res 1998:45:33-8.

4 Friedman J, Friedman H. Fatigue in Parkinson's disease. Neurology 1993;43:2016-18.

5 Karlsen K, Larsen JP, Tandberg E, et al. Fatigue in patients with Parkinson's disease. Mov Disord 1999;14:237-41.

6 Lou JS, Kearns G, Oken B, et al. Exacerbated physical fatigue and mental fatigue in Parkinson's disease. Mov Disord 2001;16:190-6.

7 Van der Werf SP, van den Broek HL, Anten HW, et al. Experience of severe fatigue long after stroke and its relation to depressive symptoms and disease characteristics. Eur Neurol 2001;45:28-33.

8 Paul RH, Cohen RA, Goldstein JM, et al. Fatigue and its impact on patients with myasthenia gravis. Muscle Nerve 2000;23:1402-6.

9 Berlly MH, Strauser WW, Hall KM. Fatigue in postpolio syndrome. Arch Phys Med Rehabil 1991;72:115-18.

10 Merkies ISJ, Schmitz PIM, Samijn JPA, et al. Fatigue in immune-mediated polyneuropathies. Neurology 1999;53:1648-54.

11 Herlofson K, Larsen JP. The influence of fatigue on health-related quality of life in patients with Parkinson's disease. Acta Neurol Scand 2003;107:1-6.

12 Fisk JD, Pontefract A, Ritvo PG, et al. The impact of fatigue on patients with multiple sclerosis. Can J Neurol Sci 1994;21:9-14.

13 Werf SP van der. Determinants and consequences of experienced fatigue in chronic fatigue syndrome and neurological conditions [dissertation]. Niimegen: University Nijmegen, 2003.

14 Teunissen LL, Eurelings M, Notermans NC, et al. Quality of life in patients with axonal polyneuropathy. J Neurol 2000;247:195-9.

15 Pfeiffer G, Wicklein EM, Ratusinski T, et al. Disability and quality of life in Charcot-Marie-Tooth disease type I. J Neurol Neurosurg Psychiatry 2001;70:548-50

16 Piccininni M, Falsini C, Pizzi A. Quality of life in hereditary neuromuscular diseases. Acta Neurol Scand 2004;109:113-19.

17 Padberg GW, Lunt PW, Koch MC, et al. Diagnostic criteria for facioscapulohumeral muscular dystrophy. Neuromusc Disord 1991;1:231-4. 18 Harper PS. Myotonic dystrophy, 3rd ed. London: Harcourt Publishers, 2001.

19 Gabreels-Festen AA, Bolhuis PA, Hoogendiik JE, et al. Charcot-Marie-Tooth disease type 1A: morphological phenotype of the 17p duplication versus PMP22 point mutations. Acta Neuropathol (Berl) 1995;90:645-9.

20 Harding AE, Thomas PK. The clinical features of hereditary motor and sensory neuropathy types I and II. Brain 1980;103:259-80.

21 Harding AE. From the syndrome Charcot, Marie and Tooth to disorders of peripheral myelin proteins. Brain 1995;1 18:809-18.

22 Vercoulen JH, Swanink CM, Fennis JF, et al. Dimensional assessment of chronic fatigue syndrome. J Psychosom Res 1994;38:383-92.

23 Vercoulen JH, Hommes OR, Swanink CM, et al. The measurement of fatigue in patients with multiple sclerosis. A multidimensional comparison with patients with chronic fatigue syndrome and healthy subjects. Arch Neurol 1996;53:642-9.

24 Servaes P, Verhagen S, Bleijenberg G. Determinants of chronic fatigue in disease-free breast cancer patients: a cross-sectional study. Ann Oncol 2002;13:589-98.

25 Werf SP van der, Broek HL van den, Anten HW, et al. Experience of severe fatigue long after stroke and its relation to depressive symptoms and disease characteristics. Eur Neurol 2001;45:28-33.

26 Vries M de, Soetekouw PM, Meer van der JW, et al. Fatigue in Cambodia veterans. QJM 2000;93:283-9.

27 Van der Zee K, Sanderman R. Het meten van de algemene gezondheidstoestand met de RAND-36: Een handleiding. [SF-36, Manual Dutch version]. Groningen: Noorderlijk Centrum voor Gezondheidsvraagstukken, 1993.

28 Dittner AJ, Wessely SC, Brown RG. The assessment of fatigue, a practical guide for clinicians and researchers. J Psychosom Res 2004;56:157-70.

29 Vercoulen JH, Alberts M, Bleijenberg G. De checklist Individual Strength (CIS), [The Checklist Individual Strength]. Gedragstherapie, 1999;32:131-6.

30 Ware JE, Sherbourne CD. The MOS 36-item short-form health survey (SF-36). Conceptual framework and item selection. Med Care 1992;30:473-83.

31 Emery AEH. Diagnostic criteria for neuromuscular disorders, 2nd ed. London: Royal Society of Medicine Press, 1997.

32 Harper PS, van Engelen BGM, Eymard B, et al. Myotonic dystrophy: present management, future therapy. New York: Oxford University Press, 2004.

33 Rubinsztein JS, Rubinsztein DC, Goodhurn S, et al. Apathy and hypersomnia are common features of myotonic dystrophy. I Neurol Neurosurg Psychiatry 1998;64:510-15.

34 Werf van der S, Kalkman J, Bleijenberg G, et al. The relation between daytime sleepiness, fatigue, and reduced motivation in patients with adult onset myotonic dystrophy. J Neurol Neurosurg Psychiatry 2003;74:138-9. 